\title{
Integrated Reporting Disclosure and Its Implications on Investor Reactions
}

\author{
I Gusti Ketut Agung ULUPUI ${ }^{1}$, Yunika MURDAYANTI², Muhammad YUSUF ${ }^{3}$, \\ Indra PAHALA ${ }^{4}$, Adam ZAKARIA ${ }^{5}$
}

Received: September 01, 2020 Revised: October 26, 2020 Accepted: November 05, 2020

\begin{abstract}
The purpose of this study is to analyze integrated reporting disclosure and its implications on investor reactions. The population in this study is all manufacturing companies listed on the Indonesia stock exchange from 2017 to 2019, totaling 171 companies, and the sampling technique used is purposive sampling method. The method used in this research is a quantitative description using the financial statements of manufacturing companies listed on the Indonesia stock exchange. The data analysis method used is multiple regression analysis with intervening variables using AMOS 24 software. The results of this study show a positive and significant effect of profitability (X1) and company size (X2) on integrated reporting (IR); a positive and insignificant effect of stakeholder pressure (X3) on integrated reporting (IR); a positive and significant effect of profitability (X1) and stakeholder pressure (X3) on investor reactions (Y); a positive and insignificant effect of firm size (X2) and integrated reporting (IR) on investor reactions (Y). Suggestions are that in further studies, we can increase the sample size by including other industries, and in addition to using annual reporting, we can also use other sources such as websites, press releases, and prospectuses to improve the robustness of this study by relying on other data sources.
\end{abstract}

Keywords: Profitability, Company Size, Stakeholder Pressure, Integrated Reporting, Investor Reactions

JEL Classification Code: M40, M41, M48

\section{Introduction}

With the advent of globalization, all types of businesses are required to prepare financial statements that are easy to understand as well as can be compared with other similar businesses. In the digital era and technological developments, the flow of information is so fast that Internet technology has changed one's view of getting information, including

\footnotetext{
${ }^{1}$ First Author. Lecturer, Faculty of Economics, Universitas Negeri Jakarta, Indonesia. Email: Igka-Ulupui@unj.ac.id

${ }^{2}$ Corresponding Author. Lecturer, Faculty of Economics, Universitas Negeri Jakarta, Indonesia [Postal Address: Pesona Khayangan Blok DR no. 9 Depok Jawa Barat 16411, Indonesia]

Email: yunika_murdayanti@unj.ac.id

${ }^{3}$ Lecturer, Faculty of Economics, Universitas Negeri Jakarta, Indonesia. Email: myusuf_fe@unj.ac.id

${ }^{4}$ Lecturer, Faculty of Economics, Universitas Negeri Jakarta,

Indonesia. Email: indrapahala@unj.ac.id

${ }^{5}$ Lecturer, Faculty of Economics, Universitas Negeri Jakarta, Indonesia

(c) Copyright: The Author(s)

This is an Open Access article distributed under the terms of the Creative Commons Attribution Non-Commercial License (https://creativecommons.org/licenses/by-nc/4.0/) which permits unrestricted non-commercial use, distribution, and reproduction in any medium, provided the original work is properly cited.
}

in the world of business accounting. The development of decision-making needs has led to new content in accounting, especially financial statements. The importance of financial reports is to meet the needs of users of financial reports where such users, in their capacity as providers of financial resources, use these reports for economic decision making as well as information on investors and creditors. However, in addition to these needs, it is essential that financial reports provide information about the effects of the firm's existence on the social and natural environment (Kustiani, 2017).

In 2011, International Integrated Reporting Committee (IIRC) supported by Global Reporting Initiatives (GRI) developed a new reporting model called Integrated Reporting $(<\mathrm{IR}>)$ as a solution to address the need for finding new ways to measure and communicate corporate value creation. According to the IIRC, Integrated reporting (IR) is a process founded on integrated thinking that results in a periodic integrated report by an organization about value creation over time and related communications regarding aspects of value creation. $<$ IR $>$ itself is defined as a concise and integrated communication on how the strategy, governance, remuneration, performance, and prospects of an organization result in value creation in the short-, medium-, and long-term. 
IR provides a broader reporting approach than traditional reporting that is currently available (Kustiani, 2017).

In December 2013, the IIRC framework was issued which provides a starting framework for companies to promote integrated thinking and reporting in an integrated manner. $<\mathrm{IR}>$ combines several reports consisting of financials, management records, governance, and remuneration, as well as sustainability reports into one reporting package to explain an organization's ability to create value and maintain its value in the long term. $<\mathrm{IR}>$ presents together material information about an organization's strategy, governance, remuneration, performance, risks, and prospects that reflect the commercial, social and environmental context in which it operates. The $<\mathrm{IR}>$ standard has been supported by business people and investors from more than 25 countries, as well as several international standard drafting agencies sitting on the council that oversees the $<\mathrm{IR}>$ standards drafting board. Among them were representatives of the IASB (which compiled the IFRS), IFAC (International Accountants Organization), and GRI (Nazier \& Umiyati, 2015).

Today's organizations have utilized mechanisms outside of financial reporting to meet increasing stakeholder demands for information about the organization. Whereas in practice issuing the sustainability report issue is currently a major business practice. One criticism of this practice is the volume of information produced is often without identifying strategic or financial implications and/or related information in annual reports, which makes it less useful for users of information. particularly providers of financial capital (Kustiani, 2017). A further claimed benefit of $<\mathrm{IR}>$ is that it combines the most material elements of an organization's separate reporting thread into a concise, coherent report. Thus, not only reporting the most strategic and relevant information, which is important for investors' investment decisions (Cheng et al., 2015) but also shows the connectivity between these elements. This can explain and influence an organization's ability to create and sustain value in the short-, medium-, and long-term (IIRC, 2013a in Zhou, Simnett, \& Green, 2017). $<\mathrm{IR}>$ is still an emerging phenomenon so empirical research on it is new and rare. Among the limited empirical studies on $<\mathrm{IR}>$, Serafeim (2014), and Zhou et al. (2017) provide evidence of the value of this reporting form by examining the firm's investor base practicing $<\mathrm{IR}>$.

Pavlopoulos, Magnis, \& Iatridis (2019) explained that the $<\mathrm{IR}>$ does not place undue emphasis on short-term financial performance. Using $<\mathrm{IR}>$, management can oversee the business daily (Eccles \& Krzus, 2010; IIRC, 2013a; Potter \& Soderstrom, 2014; Zhou et al., 2017) and can inform investors and stakeholders about the company's strategy (Abeysekera, 2013). The IIRC notes that $<\mathrm{IR}>$ shows the linkages between strategy, governance, and financial performance and the social, environmental, and economic contexts in which it operates. $<\mathrm{IR}>$ not only handles investors but also other stakeholders, such as customers, suppliers, and banks (Krzus, 2011; Pavlopoulos et al., 2019).

Rouf (2011), Bidaki \& Hejazi (2014), and Kurniawan and Wahyuni (2018) proved that profitability has a positive relationship with the level of corporate information disclosure. The Corporate Governance (CG) mechanism, which is described by the board of directors as to how a board directs and manages the corporation, taking into account the impact of decisions on stakeholders including suppliers, customers, employees, shareholders, and communities, has an important role in the level of quality and transparency of information to these stakeholders.

Company size is one of the factors that influence the sustainability of voluntary disclosure practices in companies (Lan et al., 2013; Ghasempour \& Atef, 2014; Albitar, 2015; Ghani et al., 2018). Managers in large companies recognize that the size of their company has the advantage of having well-executed voluntary disclosure practices. Meanwhile, small companies will be threatened by their existence from their competitive position due to the disclosure of company information.

Stakeholder pressure is the pressure exerted by parties directly related to the company (stakeholders) on company managers to disclose all information, both financial information and non-financial information which can be called comprehensive information. According to Galani et al. (2011) and Kurniawan and Wahyuni (2018), large companies have a responsibility to the public to disclose their business activities because this will form "public knowledge". Strong pressure from stakeholders will spur company managers to further disclose financial and non-financial information.

Business, investors, capital markets, and the economy at large will depend on the quality of relevant information that can provide an efficient and effective allocation of resources to promote a healthy, transparent, ethical and sustainable investment climate. One of the relevant information for investors to make a decision is $<\mathrm{IR}>$. Akker (2017) found that investors in companies that present $\mathrm{I}=<\mathrm{IR}>$ are proven to get low cumulative abnormal returns.

Based on the above background, the purpose of this study is to determine the profitability, company size, and stakeholder pressure that affect investors' reactions with $<\mathrm{IR}>$ as an intervening variable.

\section{Literature Review}

\subsection{Integrated Reporting $(<I R>)$}

Jensen and Berg (2012) and Akker (2017) disclosed, that there is an increasing demand for consolidating financial and non-financial information into one report. The report, in turn, should provide a comprehensive view of the company about its objectives, relationship to financial performance, 
and economic, ecological, and social activities. The IIRC introduces a new idea $<\mathrm{IR}>$. IIRC was formed in 2010 by the Global Reporting Initiative (GRI) and the Prince of Wales' Accounting for Sustainability (A4S) project. $<\mathrm{IR}>$ is an integrated report that contains a brief communication about how the organization's strategy, governance, performance, and prospects, in the context of its external environment, lead to value creation in the short- medium-, and long-term (IIRC, 2013). IR is currently being used by companies in both the public and private sectors.

$<$ IR $>$ shows the holistic picture of a company about future targets as well as links between financial performances and non-financial performances (Jensen \& Berg, 2012; Hoque, 2017). In favor of $<\mathrm{IR}>$, practitioners and supporters of integrated reporting assert that $<\mathrm{IR}>$ brings more transparency on the corporate commitment to sustainability by showing the links between financial and sustainable performance in a single document (Adams, 2013; Eccles \& Krzus, 2010; Hoque, 2017). Companies are permitted not to present reporting in IR because it is voluntary. The application of $<\mathrm{IR}>$ presentations is part of the company's legitimacy strategy as well as through a stakeholder approach (Dosinta, Brata, \& Heniwati, 2018).

\subsection{Profitability}

Yuliawati and Sukirman (2015) argue that company profitability is the ability of a company to generate profit resulting from sales and investment income and aims to increase shareholder value. The profitability of the company is important for companies that want to maintain the strength and financial condition of the company in addition to maintaining its business growth.

Profitability reflects the ability to generate a profit of a unit of cost or input or output that reflects the business results. When the business activities of industrial enterprises are favorable, creating conditions for increasing profits, the profitability of enterprises also increases (Dang et al., 2020). Rouf (2011), Bidaki and Hejazi (2014), and Kurniawan and Wahyuni (2018) proved that profitability had a positive relationship with the company's information disclosure level. Previous research stated that the company's profitability level has a significant impact on corporate reports.

Sheridan et al. (2011) stated profitability is the ability of the company to get a profit or investment return. In general, the profitability of a company can be calculated using the profitability ratio which is a ratio to assess the company's ability to seek profit. Profitability ratios can also be used to measure the level of management effectiveness of a company. Companies that have high profitability will attract investors so that the company value increases in the hope of getting high profits; therefore, this is the basis for using ROA in this study.

\subsection{Company Size}

Company size is an identification of the size of the company, large or small. The size of a company can be seen based on the total asset value, total sales, market capitalization, number of workers, and so on (Yuliawati \& Sukirman, 2015). Company size is a measure to decide the size of a company that is shown or valued by total assets, total profit, tax expense, total sales, and others (Brigham \& Houston, 2010). The greater the level of income, total assets, and total capital owned, the stronger the performance of the company. Companies that have a large size tend to have a large value on these items. The bigger the asset, the more capital invested. The more sales, the more money circulation and the greater the market capitalization, the bigger the company will have a good name in the eyes of the public.

Kurniawan and Wahyuni (2018) and Galani et al. (2011) found that a company with a large size may have sufficient resources to reduce the information production cost in the company's annual report, and then this process will increase the disclosure level. Frias-Aceituno et al. (2013) explained that the company's size is one of the important factors in the dissemination of $<\mathrm{IR}>$.

\subsection{Stakeholder Pressure}

Stakeholder theory (ST) postulates that an organization/ company should not only pay attention to the proprietors of the firm and profitability but also take care of the society, environment, and the economy in which it functions. Adoption and implementation of $\langle\mathrm{IR}>$ can be perceived as a tool to get approval to operate in the society and to avoid negative movements from pressure groups (Aluchna et al., 2019; Ara \& Harani, 2020). ST implicates that certain disclosures are aimed to provide organizations' resources to certain stakeholders. Stakeholders are an important part of the company, a company cannot operate without stakeholders. Stakeholders greatly influence the survival of the company (Ara \& Harani, 2020).

In the current market economy, auditing is one of the sectors interested in and trust by society. The demand of society for the auditing profession is rapidly increasing which requires auditors and audit firms to improve both professional competence and audit services. Audit firms have not focused on evaluating control risks, potential risks, and internal control system, but mainly based on subjective opinions of auditors, and pressure on the time to complete auditor's work. On the other hand, audit firms, which want to survive and develop, are also under pressure on revenue and competition. Therefore, the quality and duration of the audit have a great influence on the choices of clients (Nguyen, Ngo, \& Le, 2020).

Stakeholder pressure is the pressure exerted by parties that are directly related to the company (stakeholder) and on company managers to disclose all information, both financial and 
non-financial information which can be called comprehensive information. (Kurniawan \& Wahyuni, 2018). Pressure from parties that are directly related to the company (stakeholders) can influence decision-making by companies in various contexts, depending on what position these stakeholders are in.

\subsection{Investor Reactions}

Investors are individuals, groups, or legal entities investing in a particular business unit. Investors' reactions will be seen when there is a company price that has experienced a significant increase or decrease in the security concerned at the time of the earnings announcement. Capital market equity investors are seen as important stakeholders when managers make voluntary disclosure decisions (Terblanche \& De Villiers, 2019). Managers voluntarily disclose information to meet investor expectations, which benefits the managers in terms of enhanced career prospects and bonus remuneration. Investors' information needs are important since their assessment of companies' risks and opportunities will influence share prices and thereby managers' prospects and bonuses. Where companies do not disclose the information needed to fully assess risks and returns, investors protect themselves by assuming the worst-case scenario, which is known as adverse selection (Terblanche \& De Villiers, 2019).

$<$ IR $>$ aims to advance and improve corporate reporting by emphasizing the interconnections between different types of information presently reported in separate strands. Serafeim (2014) provided evidence on the value of this form of reporting by examining the investor base of companies that practice $<\mathrm{IR}>$. Informational equivalent disclosures that vary only in their ease of processing can have differential effects on market prices. Serafeim noted a relation between $<\mathrm{IR}>$ and the investor clientele concerning the investment horizon, however, he also noted that it is not clear how investors change capital allocation decisions based on the information within $<\mathrm{IR}>$. Furthermore, as the data from the 'Asset4 database' do not provide links to the content elements of $<\mathrm{IR}>$, Serafeim was not able to determine which elements of $<\mathrm{IR}>$ were most effective in attracting long-term investors. (Zhou et al., 2017).

Negative words written in financial and economic articles by newspapers and media can identify subsequent investor sentiment and also sensational financial news and newspaper articles can easily drive stock market price, especially if the news comes from reliable sources (Nguyen \& Pham, 2018). It can be said that the change is striking if there is a significant difference between the actual return and the expected return and it can be said that the actual return is not in line with the expected return.

\subsection{Previous Research Studies}

Kurniawan and Wahyuni (2018) showed that company size has a positive and significant effect and stakeholder pressure has a negative and significant effect on the company's ability to perform $<\mathrm{IR}>$. The results also show that company profitability, managerial ownership, and institutional ownership do not influence the company's ability to carry out $<\mathrm{IR}>$. The research of Ghani et al. (2018) shows that the level of $<\mathrm{IR}>$ disclosure among real property companies has increased over time, their level of integrated reporting practices is still low. This study also shows that only firm size and audit significantly affect the level of $<\mathrm{IR}>$ practice among real property firms in Malaysia. Leverage, return on assets, return on equity and liquidity do not show a significant relationship with the level of $<\mathrm{IR}>$.

Pavlopoulos et al. (2019) explained the quality of IR disclosure increases the value relevance of accounting information and can create value indicated by a positive relationship between firm performance and the quality of IR disclosure, and the level of quality of IR disclosure is more significant when firms tend to show a higher value relevance of summary accounting information. Finally, more effective use of IR results in abnormal returns on stocks that are positively associated with earnings quality.

Terblanche and De Villiers (2019) findings implied $<$ IR $>$ is likely to increase intellectual capital (IC) disclosures and also that future IC disclosure research may have to take into account whether companies prepare $\mathrm{a}<\mathrm{IR}>$. In other words, evidence supports the hypothesis that $<\mathrm{IR}>$ leads to more IC disclosure, specifically to a greater variety of IC items disclosed and to a greater emphasis on the IC in the report. Zhou et al. (2017) study results which were obtained after controlling for factors relating to financial transparency and the issuance of standalone non-financial reports, suggest $<\mathrm{IR}>$ provides incrementally useful information to the capital market over and above existing reporting mechanisms. Akker (2017) found that the $<\mathrm{IR}>$ group has a significantly lower bid-ask spread relative to the control group and $<\mathrm{IR}>$ is negatively associated with information asymmetry.

Hypotheses:

H1: Profitability is significantly and positively related to integrated reporting

H2: Company size is significantly and positively related to integrated reporting.

H3: Stakeholder pressure is significantly and positively related to integrated reporting

H4: Profitability is significantly and positively related to investor reactions

H5: Company size is significantly and positively related to investor reactions

H6: Stakeholder pressure is significantly and positively related to investor reactions

H7: Integrated reporting is significantly and positively related to investor reactions 


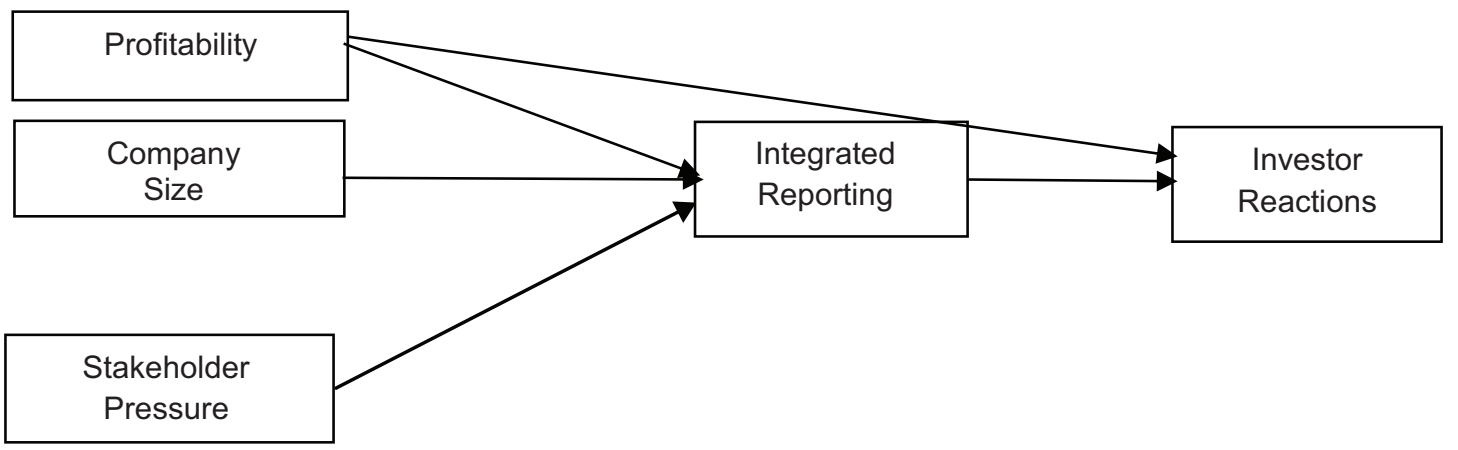

Figure 1: Research Framework

\section{Research Methods}

\subsection{Research Design}

This research uses quantitative research methods, which is a type of systematic scientific research on parts of phenomena and their relationships by collecting, processing, and analyzing data with statistical techniques, then drawing general conclusions to prove the existence of integrated reporting as a tool for accounting disclosure for substantial financial reporting and its implications for investor reactions.

\subsection{Population and Sample}

The population used in this study are manufacturing companies listed on the Indonesia Stock Exchange for the period 2017-2019. Manufacturing companies were chosen as objects in this study because they account for a large contribution to Indonesia's Gross Domestic Product (GDP). There are 171 manufacturing companies listed on the Indonesia Stock Exchange from the 2017-2019 period. This population selection is also supported by Nguyen and Nguyen (2020). Manufacturing is the most important sector in the economy in Vietnam which facilitates the government to set up tighter and more appropriate regulations and policies to promote the stable development of the stock market, create fairness among listed enterprises, and protect the interests of investors. The sampling technique used is the purposive sampling method, namely, sampling selected according to the research criteria.

\subsection{Variable Operationalization}

\section{Investor Reactions}

Investor reactions are positive or negative responses given by individuals, groups, or legal entities investing as a result of providing information conveyed by company management (Jao et al., 2020). This study uses stock returns as a measurement of investor reactions. This is because investors 'reactions are investors' actions that are reflected in stock returns (Jao et al., 2020). Stock return is the return obtained from investment, in the form of profits on share ownership (dividends) or the difference between the current period's share price and the previous period (capital loss/ gain).

\section{Profitability}

Profitability is the level of the company's ability to generate operating profits concerning sales, total assets, and capital (Kurniawan \& Wahyuni, 2018). In this study, profitability is measured by the Return on Asset (ROA) ratio formulated as follows:

$$
\text { Return On Asset }(R O A)=\frac{\text { Net income before tax }}{\text { Total assets }} \times 100 \%
$$

\section{Company Characteristics}

Company size is an identification of the size of a company, which can be seen from the total asset value, total sales, market capitalization, number of workers, and so on (Yuliawati \& Sukirman, 2015). In measuring company size variables, researchers use the same proxy as Kurniawan and Wahyuni (2018) research, which is measured by the natural logarithm of total assets.

$$
\text { Company Size }=\operatorname{Ln}(\text { Total Assets })
$$

\section{Stakeholder Pressure}

The stakeholder pressure variable in this study is defined as pressure from the government and pressure from the majority shareholder on the company's activities. The measurement of the stakeholder pressure variable is based on the total shares owned by the government with the total stock of the majority shareholders (Kurniawan \& Wahyuni, 2018).

\section{Integrated Reporting $<\mathrm{IR}>$}

$<\mathrm{IR}>$ is a brief communication on how an organization's strategy, governance, performance, and prospects, in the 
context of its external environment, lead to value creation in the short-, medium-, and long-term (IIRC, 2013). This study uses the $<\mathrm{IR}>$ Index as a research instrument (proxy) to determine the level of application of $<\mathrm{IR}>$ as has been used in previous studies (Ghani et al., 2018; Kurniawan \& Wahyuni, 2018). The total number of items that must be disclosed is 42 items. Each item will be rated "1" if the item is disclosed by the company, while " 0 " if the company does not disclose the item.

$$
I R \text { Value }=\frac{\text { The total items disclosed on the report }}{\text { Total items according to the IR Framework }}
$$

\subsection{Data Analysis Technique}

The data analysis technique in this study uses quantitative analysis. This analysis technique is carried out on data obtained from secondary data and is used to analyze data in the form of numbers and calculations using statistical methods. The data must be classified in certain categories by using certain tables to make it easier to analyze with the help of the AMOS 24 program (Ghozali, 2017) and use path analysis techniques.
Structural Equations 1 :

$\mathrm{M}(I R)=\beta \operatorname{PROFIT}(\mathrm{X} 1)+\beta \operatorname{SIZE}(\mathrm{X} 2)+\beta \mathrm{SP}(\mathrm{X} 3)+\mathrm{e}_{1}$

Structural Equations 2 :

$\mathrm{Y}(\mathrm{REACT})=\beta \mathrm{PROFIT}(\mathrm{X} 1)+\beta \operatorname{SIZE}(\mathrm{X} 2)+\beta \operatorname{SP}(\mathrm{X} 3)$ $+\beta I R+e_{2}$

Independent Variables : Profitability, Company Size, Stakeholder Pressure

Dependent Variable : Investor Reactions

Intervening Variable : Integrated Reporting

\section{Results and Discussion}

\subsection{Results}

\subsubsection{Descriptive Statistics}

Descriptive statistical analysis is used to determine the statistical value of the related variables used in the study.

The output results show that the investor reactions (Y) with 279 sample companies have a minimum value of -0.868525896 and a maximum value of 5.762295082 , while the average obtained for variable $\mathrm{Y}$ is 0.042245687 or $4.225 \%$, The standard deviation value is 0.534400763 showing that the standard deviation value obtained is good enough.

Table 1: Items contained in the IR index

\begin{tabular}{|l|l|c|}
\hline No. & \multicolumn{1}{|c|}{ Element Content } & Number of Items \\
\hline 1 & Organization and external environment overview & 5 \\
\hline 2 & Governance & 5 \\
\hline 3 & Business Model & 5 \\
\hline 4 & Risks and Opportunities & 5 \\
\hline 5 & Strategy and Resource Allocation & 5 \\
\hline 6 & Performance & 5 \\
\hline 7 & Overview & 5 \\
\hline 8 & Basis of Preparation and Serving & 5 \\
\hline
\end{tabular}

Table 2: Descriptive Statistical Analysis Results

\begin{tabular}{|l|c|c|c|c|c|}
\hline & N & Minimum & Maximum & Mean & Std. Deviation \\
\hline X1 & 279 & -0.6057 & 0.727854 & 0.06913 & 0.134624 \\
\hline X2 & 279 & 25.21557 & 33.47373 & 28.45216 & 1.610565 \\
\hline X3 & 279 & $16,423,425$ & $107,594,221,133$ & $3,725,235,819$ & $11,829,995,201$ \\
\hline Y & 279 & -0.868525896 & 5.762295082 & 0.042245687 & 0.534400763 \\
\hline IR & 279 & 0.466666667 & 1.166666667 & 0.884707288 & 0.131207209 \\
\hline Valid N (listwise) & 279 & & & & \\
\hline
\end{tabular}


The output results show that profitability (X1) has a minimum value of -0.6057 and a maximum value of 0.727854, while the average value of the profitability variable is 0.06913 , therefore this implies that the ability to generate profit by manufacturing companies listed on the Indonesia stock exchange in 2017-2019 is still quite low and the standard deviation value of the profitability variable is 0.134624 .

The output results show that company size (X2) has a minimum value of 25.21557 and a maximum value of 33.47373. The average value for this variable is 28.45216 and the standard deviation value is 1.610565 showing that the standard deviation value obtained is good enough.

The output results show that stakeholder pressure (X3) has a minimum value of $16,423,425$ and a maximum value of $107,594,221,133$, while the average value is $3,725,235,819$ with a standard deviation value of $11,829,995,201$.

The output results show that the integrated reporting (IR) variable with 279 sample companies has a minimum value of 0.466666667 and a maximum value of 1.166666667 , while the average obtained for the IR variable is 0.884707288 , The standard deviation value is 0.131207209 showing that the standard deviation value obtained is good enough.

\subsubsection{Data Normality}

Evaluation of normality is carried out using the criteria of critical ratio skewness value and kurtosis value. In this case, the value of the two ratios which has a value smaller than the absolute value of 2.58 , means that the data is normally distributed. From the results of data processing shown in the table above, it can be seen that the results of normality testing show that the CR value for multivariate is 4.983 which is below 10 , so it can be said that there is no evidence that the distribution of the observed variable data is abnormal.

\subsubsection{Evaluation of Outliers}

Multivariate outliers, namely the evaluation of multivariate outliers, needs to be done because even though the analyzed data shows no outliers at the univariate level, these observations can become outliers when combined. In calculating the Mahalanobis distance based on the chi-square value at degrees of freedom of 7 at the level of $p<0.001$, it is $(\mathrm{df} 7, \mathrm{p}<0.001)=24.32$ (based on the $\mathrm{x} 2$ distribution table). From the results of data processing, it can be seen that the maximum Mahalanobis distance is 24.32 with 32 outliers.

\subsubsection{Evaluation of Multicollinearity and Singularity}

The next data test is for multicollinearity and singularity in a combination of variables. From the results of data processing, the determinant value of the sample covariance matrix is

Determinant of sample covariance matrix $=$ 64899302135933.100.

From the results of data processing, it can be seen that the determinant of the sample covariance matrix is far from zero. Thus, it can be said that the research data used did not contain multicollinearity and singularity.

\subsubsection{Interpretation of Hypothesis Testing Results}

Statistically, the independent variables provide a significant effect of $15.8 \%$. The following is a picture of the model of the influence of profitability, company size, and stakeholder pressure with $<\mathrm{IR}>$ as an intervening variable and its implications for investor reactions :

Based on the picture above, there are the results of hypothesis testing at a significance of p-value $<0.005$ and the direction of the variable relationship by paying attention to the value in the estimate column. The following is a table of hypotheses testing for each variable:

The significance of independent variables in this study indicated by a P-Value is less than the standard of significance (P-Value $<0.05$ ), so it can be concluded that H1, H2, H4, H6 are accepted, but H3, H5, and $\mathrm{H} 7$ are not accepted.

Table 3: Normality Testing

\begin{tabular}{|l|c|c|c|c|c|c|}
\hline Variable & Min & Max & Skew & C.R. & Kurtosis & C.R. \\
\hline X3 & $16,423,425$ & $9,391,678,000$ & 1.944 & 12.471 & 3.165 & 10.154 \\
\hline X1 & -0.255 & 0.296 & -0.119 & -0.766 & 1.604 & 5.147 \\
\hline X2 & 25,216 & 32,201 & 0.455 & 2.916 & -0.149 & -0.478 \\
\hline IR & 0.533 & 1.167 & -0.142 & -0.913 & -0.744 & -2.386 \\
\hline Y & -0.869 & 1.190 & 0.691 & 4.433 & 1.883 & 6.042 \\
\hline Multivariate & & & & & 5.305 & 4.983 \\
\hline
\end{tabular}




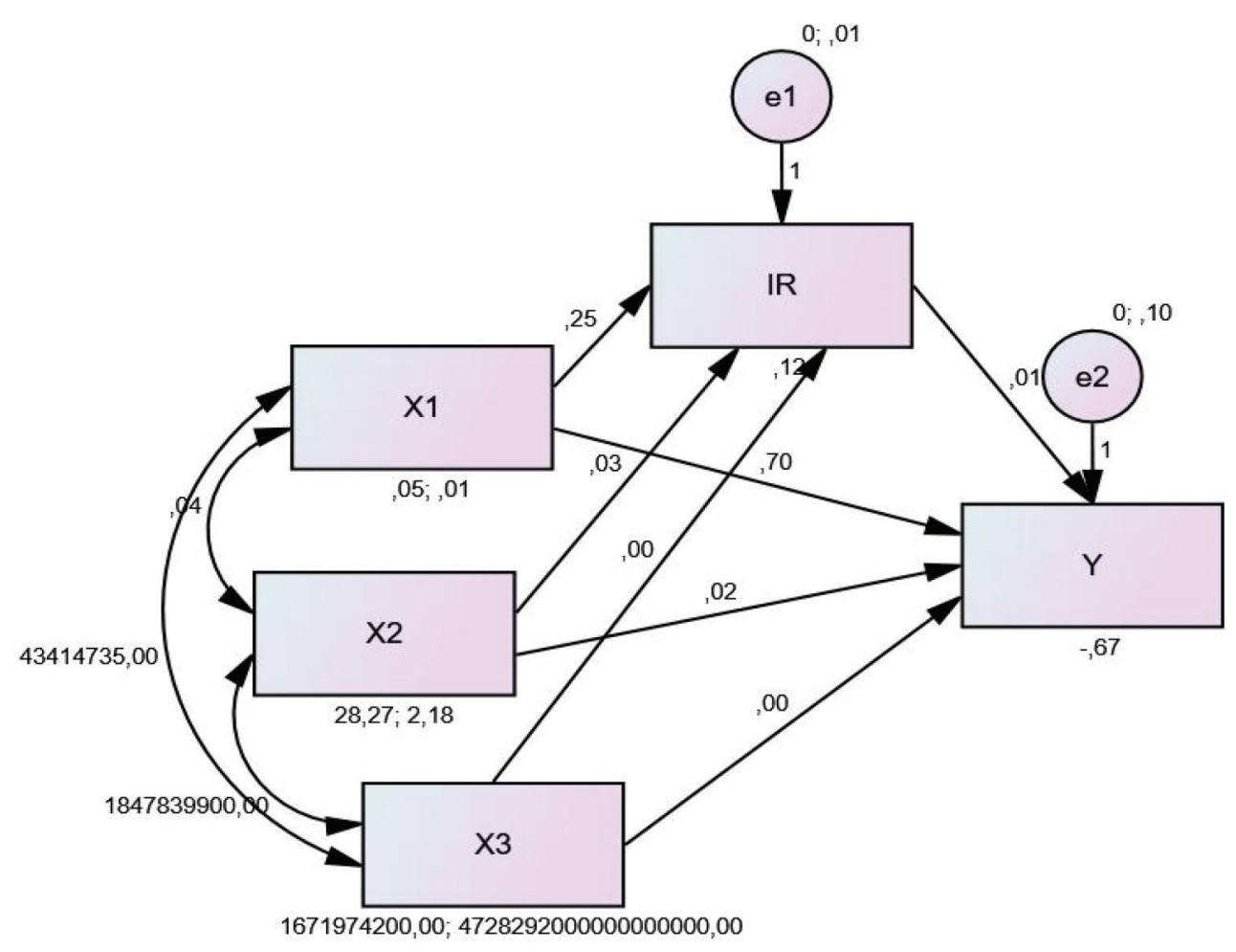

Figure 2: Regression Model

Table 2: P-Value Test Results

\begin{tabular}{|l|c|c|c|c|c|c|c|}
\hline & & & Estimate & S.E. & C.R. & P & Label \\
\hline$I R$ & $<---$ & X2 & 0.027 & 0.006 & 4.203 & 2.724 & 0.006 \\
\hline$I R$ & $<---$ & X1 & 0.246 & 0.090 & 0.113 & 0.910 & 0.006 \\
\hline IR & $<---$ & X3 & 0.000 & 0.000 & 2.765 & 1.307 & 0.191 \\
\hline$Y$ & $<---$ & X1 & 0.696 & 0.252 & 0.018 & 0.008 & 0.953 \\
\hline$Y$
\end{tabular}

\subsection{Discussion}

Company Profitability is Significantly and Positively Related to Integrated Reporting $(<I R>)$

Hypothesis 1 has a significance value of 0.006 less than 0.05 with a positive effect stating that profitability (X1) on $<\mathrm{IR}>$ can be accepted.

The results of this study are in line with research by Nguyen \& Nguyen (2020) who showed that the more profitable the business, the higher the level of sustainable development information disclosure. This shows that businesses with high profits will increase the disclosure of sustainable development information. Yuliawati and Sukirman (2015) showed that the increase in profitability achieved by the company will increase the CSR disclosure by the company.

In contrast, the results of this study are not in line with research by Kurniawan and Wahyuni (2018) who showed that the level of the company's profitability did not affect the company's capability to perform $<\mathrm{IR}>$. However, Jao et al. (2020) stated that companies that experience an 
increase in profitability, market performance, and strengthen their competitive advantage are signals to investors that a company with a good corporate reputation is the main driver of the company's sustainability performance.

The results of this study are also not in line with research by Ahmed Haji and Anifowose (2016) who stated that none of the other control variables, that is, firm size (SIZE) and profitability (ROA), is significant in explaining the extent and quality of $\langle\mathrm{IR}>$ practice and research. But Pavlopoulos et al. (2019) who concluded positive statistical results and associated it at a significant $5 \%$ level with the ROA, stated that firms that exhibit higher $<\mathrm{IR}>$ disclosure quality are outperforming.

The results of this study have shown that the higher the profitability, the better the quality of disclosure contained in $<\mathrm{IR}>$ and vice versa. This is strengthened by the annual report data of manufacturing companies in Indonesia that profitability can increase the company's ability to make business strategies and competitive advantage by producing quality disclosures and high $<\mathrm{IR}>$.

\section{Company Size is Significantly and Positively Related to Integrated Reporting $(<I R>)$}

Hypothesis 2 has a significance value of 0.000 less than 0.05 with a positive effect stating that company size (X2) on $<\mathrm{IR}>$ is acceptable.

The results of this study are in line with research by Kurniawan and Wahyuni (2018) who found that the company's size is one of the factors that support the integrated reporting process. Another explanation describes that the company with a large size has high ability and sufficient resources to create their integrated reporting process. The $<\mathrm{IR}>$ process requires coordination from all parts of the company and reporting costs are very high. Nguyen and Nguyen (2020) concluded that firm size has a statistically positive effect on the disclosure of sustainable development information. Large companies often have great economic potential, so they can disclose more information about sustainable development. Yuliawati and Sukirman (2015) concluded that the greater the size of the company, the more CSR disclosures the company makes. Ghani et al. (2018) concluded that $<\mathrm{IR}>$ and company size are positively significant at 0.01 but minimally correlated between the two variables. This study also shows that the company size measured by the total asset and the audit firm size provides a powerful explanatory variable when related to $<\mathrm{IR}>$.

However, the results of this study are not in line with the research by Ahmed Haji and Anifowose (2016)who stated that none of the other control variables, that is, firm size (SIZE) and profitability (ROA), is significant in explaining the extent and quality of IR practice.

The results of this study support the legitimacy theory which states that large companies will adopt social responsibility to gain legitimacy from stakeholders and try to ensure that corporate actions are according to public expectations. The size of the company greatly influences the company's ability to disclose all financial and non-financial information in $<\mathrm{IR}>$ and can describe the company's performance in the current year in support of the achievement of company goals.

\section{Stakeholder Pressure is Significantly and Positively Related to Integrated Reporting $(<I R>)$}

Hypothesis 3 has a significance value of 0.910 which is greater than 0.05 with a positive effect, stating that stakeholder pressure (X3) on $<\mathrm{IR}>$ cannot be accepted.

The results of this study are supported by Kurniawan and Wahyuni (2018), who that the stakeholder's pressure has a negative correlation with the company's capability in performing $<\mathrm{IR}>$. It means if the stakeholder's pressure increases, the companies tend to not disclose financial and non-financial information on $<\mathrm{IR}>$ (the companies have a lower ability to perform $<\mathrm{IR}>$ ).

However, the results of this study are not in line with Sadia, Tariq, and Saba (2015) and Nguyen and Nguyen (2020) who found a positive correlation between firm size and the level of disclosing sustainable development information of enterprises. Vitolla, Raimo, Rubino, and Garzoni (2019) showed that stakeholders' pressure is a key determinant of the quality of $\langle\mathrm{IR}\rangle$. Specifically, their results show how the pressure from customers, environmental protection organizations, employees, shareholders, and governments favors the publication of higher quality $<\mathrm{IR}>$.

Stakeholder's pressures are the "pressure" from the company's stakeholders to the company's management to disclose financial information and non-financial information (comprehensive information). However, the results of this study do not prove that stakeholders' pressure improves the quality of $\langle\mathrm{IR}>$. Therefore, this study is not in line with the stakeholder theory represented by the stakeholder's pressure variable and the legitimacy theory which states that the company's social and environmental disclosure is important to gain legitimacy for the company's operations from all stakeholders.

\section{Profitability is Significantly and Positively Related to Investor Reactions}

Hypothesis 4 has a significance value of 0.006 which is less than 0.05 with a positive effect, stating that profitability (X1) on investors' reactions is acceptable.

The results of this study are supported by the notion that profitability level is a measure to examine management performance in conducting business activities. High profitability is the outcome of using the company's resources 
efficiently and effectively. The corporate governance of companies listed on the SRI-KEHATI stock index and companies participating in the ISRA competition have demonstrated a strong commitment to implement the concept of sustainability in the company's business activities (Kurniawan \& Wahyuni, 2018) and good company quality will motivate investors to react and invest in stocks of that company which will lead to increase in share prices. An increasing share price will be followed by an increase in stock returns (Jao et al., 2020).

However, this research is not in line with the research by Dang et al. (2020) who stated that profitability is negatively correlated with financial risk, especially the ROA is statistically significant at $0.00 \%$, meaning that the more ROA the higher the financial risk and vice versa. To improve profitability, businesses need to improve their competitiveness to increase sales revenue and have good cost control measures.

Based on this, the high profitability of the company is one of the factors related to the company's ability to attract investor reactions. The quality of the company as indicated by the increase in company profitability strongly supports the results of this study that high profitability can have a strong influence on investors' reactions in investing their capital. High investor reaction will increase stock prices and company stock returns. Moreover, benefits obtained from increased investor reactions are that companies tend to experience increased profitability, market performance, and strengthen the company's competitive advantage.

\section{Company Size is Significantly and Positively Related to Investor Reactions}

Hypothesis 5 has a significance value of 0.191 which is greater than 0.05 with a positive effect, stating that firm size (X2) on investor reactions is unacceptable.

This research differs from the results of Kurniawan and Wahyuni (2018) who reinforced the view that companies with large size are strongly monitored by investors and the company's stakeholders. The company's reputation, which is formed from the perception of the company's effectiveness, is a good signal for investors. This good signal is because the company's reputation is the main driver of the company's sustainable performance (Jao et al., 2020). The larger companies disclosed more financial and non-financial information than small companies. The reason is that largescale companies often have many and diverse investors, therefore, the demand for information disclosure is higher (Nguyen \& Nguyen, 2020).

Based on the results of this study, the results prove that the company's reputation, which is generally seen in the size of the company, does not affect the company's effectiveness, and neither the company is regarded as trustworthy and therefore is not related to increased investor reactions. In other words, the company must be able to develop and increase stakeholder trust, ensuring stakeholders the continuous development of reports that can increase investor reaction. As for the results of the study, all the buying and selling activities (of company's stocks) by investors are not influenced by the size of the company and do not have an impact on investors' reaction in making investment decisions.

\section{Stakeholder Pressure is Significantly and Positively Related to Investor Reactions}

Hypothesis 6 has a significance value of 0.008 which is less than 0.05 with a positive effect, stating that stakeholder pressure (X3) on investor reactions is acceptable.

The results of this study are in line with the understanding that the strong stakeholder's pressure will encourage the company's management to disclose financial information and non-financial information. Companies with relatively large stakeholder groups will strive to disclose comprehensive information, including disclosing non-financial information (Kurniawan \& Wahyuni, 2018). The company's reputation has a positive and significant effect on investors' reactions. This shows that companies that have a high reputation tend to have increased investor reactions and have a fairly strong influence (Jao et al., 2020).

The results of this study indicate that the higher the pressure the stakeholders have, the higher the investor's reaction to their decision to invest. Investors consider company reputation information as relevant information, namely stakeholder pressure greatly affects company performance and the achievement of company reputation, with the effect of this pressure it is proven to produce increased investor reactions.

\section{Integrated Reporting $(<I R>)$ is Significantly and Positively Related to Investor Reactions}

Hypothesis 7 has a significance value of 0.953 which is greater than 0.05 with a positive effect, stating that $<\mathrm{IR}>$ on investor reactions cannot be accepted.

This research is not in line with the understanding that integrated reporting not only reports the most strategically relevant information, which is important for investors' investment decisions but also shows the connectivity between these elements and explains how they affect the ability of an organization to create and sustain value in the short-, medium-, and long-term (Zhou et al., 2017). If the reporting initiative is indeed helpful to such providers in assessing the prospects of companies, it is expected that some capital market benefits will accrue to the reporting companies. Zhou et al. (2017) obtained their results after the company-level characteristics relating to financial 
transparency and the issuance of standalone CSR reports are controlled for, suggesting that information contained in $<\mathrm{IR}>$ is incrementally useful to analysts and investors in addition to current reporting practices. Affan (2019) explained that the hypothesis test found a positive effect of $<\mathrm{IR}>$ toward corporate performance. The breadth of material expressed in the $<\mathrm{IR}>$ framework makes a strong relationship between stakeholders and managers resulting in the ability to read the opportunities and risks of each strategy taken, which will then automatically have an impact on the corporate's performance. Pavlopoulos et al. (2019) tests the association between the predictive power of abnormal stock returns and the level of earnings quality from $<\mathrm{IR}>$ disclosure and provides evidence in favor of the hypothesis. This implies that $<\mathrm{IR}>$ disclosure quality enhances earnings for firms with a high market value. Vitolla, Raimo, and Rubino (2019) concluded that the adoption and the quality of $<$ IR $>$ also bring potential benefits from an informational point of view. In this context, they could increase knowledge of the value creation process within the company and allow greater alignment with the needs of investors.

Based on this, the results in this study prove that good quality $<\mathrm{IR}>$ is not related to investor reactions in making investment decisions, and $<\mathrm{IR}>$ is still voluntary disclosure in Indonesia. As a result of this, $<\mathrm{IR}>$ is not related to the company's ability to carry out business strategy, which results in being less effective in communicating company information to investors.

\section{Conclusions}

In the mid of global economic uncertainty, the economic sector has become the government's spotlight to boost Indonesia's economic growth, especially in the manufacturing industry which still has a large contribution to Indonesia's Gross Domestic Product (GDP). However, if economic conditions fluctuate, investors will be very careful in investing in companies that will also have an impact on stock returns fluctuations owned by investors. Therefore, companies are challenged to produce quality annual reports by presenting all information on financial statements and non-financial reports that are more complex in $<\mathrm{IR}>$.

By empirically examining the $<\mathrm{IR}>$ disclosure in the annual report and investor reactions, the research results show a positive and significant effect of profitability (X1) and company size (X2) on integrated reporting $(<\mathrm{IR}>)$; a positive and insignificant effect of stakeholder pressure (X3) on integrated reporting $(<\mathrm{IR}>)$; a positive and significant effect of profitability (X1) and stakeholder pressure (X3) on investor reactions (Y); a positive and insignificant effect of company size $(\mathrm{X} 2)$ and integrated reporting $(<\mathrm{IR}>)$ on investor reactions $(\mathrm{Y})$.
The findings from this study point to several future research opportunities. First, this study only focuses on one type of avenue through which companies communicate to their stakeholders with $<\mathrm{IR}>$ as an intervening variable; however, future studies could use other sources such as websites, press releases, and prospectuses to improve the results of this study by relying on other data sources. Second, for the next research companies from different industrial sectors (other than the manufacturing sector) that are listed on the Indonesia Stock Exchange can be considered for in-depth investigations of $\langle\mathrm{IR}\rangle$, which will be fruitful. Third, future research could explore the relationships identified in this study in greater depth using different variables, different locations, and other methodologies.

\section{References}

Affan, M. W. (2019). Integrated reporting and corporate performance: Empirical evidence of the IIRC framework adoption. JEMA: Scientific Journal of Accounting and Management, 16(2), 181. https://doi.org/10.31106/jema.v16i2.2700

Ahmed Haji, A., \& Anifowose, M. (2016). Audit committee and integrated reporting practice: Does internal assurance matter? Managerial Auditing Journal, 31(8-9), 915-948. https://doi. org/10.1108/MAJ-12-2015-1293

Akker, M. V. (2017). The association between integrated reporting and information asymmetry. Master thesis, Erasmus University Rotterdam.

Ara, M., \& Harani, B. (2020). Integrated reporting insight: Why the organization voluntarily reports? International Journal of Scientific and Technology Research, 9(1), 3055-3069.

Brigham, E. F., \& Houston, J. F. (2010). Fundamentals of financial management (11th ed). Jakarta, Indonesia: Salemba Empat Publisher.

Dang, H. T., Phan, D. T., Nguyen, H. T., \& Hoang, L. H. T. (2020). Factors affecting financial risk: evidence from listed enterprises in Vietnam. Journal of Asian Finance, Economics, and Business, 7(9), 11-18. https://doi.org/10.13106/jafeb.2020. vol7.no9.011

Dosinta, N. F., Brata, H., \& Heniwati, E. (2018). Should value creation only be in integrated reporting? Journal of Multiparadigm Accounting, 9(2), 248-266. https://doi. org/10.18202/jamal.2018.04.9015

Ghani, E. K., Jamal, J., Puspitasari, E., \& Gunardi, A. (2018). Factors influencing integrated reporting practices among the Malaysian public listed real property companies: A sustainable development effort. International Journal of Managerial and Financial Accounting, 10(2), 144-162. https://doi.org/10.1504/ IJMFA.2018.091662

Ghozali, I. (2017). Structural equation modeling concepts and applications with the AMOS Program 24. Semarang, Indonesia: Diponegoro University Publishing Agency. 
Hoque, M. E. (2017). Why companies should adopt integrated reporting? International Journal of Economics and Financial Issues, 7(1), 241-248.

Jao, R., Hamzah, D., Laba, A. R., \& Mediaty, M. (2020). Company reputation and investor reaction: Study of companies listed on the Indonesian Stock Exchange. SEIKO: Journal of Management \& Business, 3(2), 124-133. https://doi.org/10.37531/sejaman. v3i2.597

Kurniawan, P. S., \& Wahyuni, M. A. (2018). Integrated reporting : Empirical evidence from Indonesian. Journal of Accounting and Education, 7(2), 141-155.

Kustiani, N. A. (2017). Implementation of integrated reporting elements in companies listed on the Indonesia Stock Exchange. Artha Info, 3, 44-61. https://doi.org/10.31092/jia.v3i0.38

Nazier, D. M., \& Umiyati, I. (2015). Sustainability reporting transformation towards Integrated Reporting (IR) as a reflection of the widening accountability in corporate governance. Dementia, 12(1), 1-34.

Nguyen, A. H., \& Nguyen, L. H. (2020). Determinants of sustainability disclosure: Empirical evidence from Vietnam. Journal of Asian Finance, Economics, and Business, 7(6), 73-84. https://doi.org/10.13106/jafeb.2020.vol7.no6.073

Nguyen, D. D., \& Pham, M. C. (2018). Search-based sentiment and stock market reactions: An empirical evidence in Vietnam. Journal of Asian Finance, Economics, and Business, 5(4), 45-56. https://doi.org/10.13106/jafeb.2018.vol5.no4.45

Nguyen, H., Ngo, T. K. T., \& Le, T. T. (2020). Risk of material misstatement in the stage of audit planning: Empirical evidence from Vietnamese listed enterprises. Journal of Asian
Finance, Economics, and Business, 7(3), 137-148. https://doi. org/10.13106/jafeb.2020.vol7.no3.137

Pavlopoulos, A., Magnis, C., \& Iatridis, G. E. (2019). Integrated reporting: An accounting disclosure tool for high-quality financial reporting. Research in International Business and Finance, 49, 13-40. https://doi.org/10.1016/j.ribaf.2019.02.007

Sheridan, T., Keown, A. J., \& Martin, J. D. (2011). Financial management principles and applications. (11th ed). New York, NY: Pearson.

Terblanche, W., \& De Villiers, C. (2019). The influence of integrated reporting and internationalization on intellectual capital disclosures. Journal of Intellectual Capital, 20(1), 40-59. https://doi.org/10.1108/JIC-03-2018-0059

Vitolla, F., Raimo, N., \& Rubino, M. (2019). Appreciations, criticisms, determinants, and effects of integrated reporting: A systematic literature review. Corporate Social Responsibility and Environmental Management, 26(2), 518-528. https://doi. org/10.1002/csr.1734

Vitolla, F., Raimo, N., Rubino, M., \& Garzoni, A. (2019). How pressure from stakeholders affects integrated reporting quality. Corporate Social Responsibility and Environmental Management, 26(6), 1591-1606. https://doi.org/10.1002/ csr. 1850

Yuliawati, R., \& Sukirman. (2015). Factors affecting disclosure of Corporate Social Responsibility. Accounting Analysis Journal, 4(4), 1-9. http://journal.unnes.ac.id/sju/index.php/aaj

Zhou, S., Simnett, R., \& Green, W. (2017). Does integrated reporting matter to the capital market? Abacus, 53(1), 94-132. https://doi.org/10.1111/abac.12104 